State experience. Int J Radiat Oncol Biol Phys 1988; 15: 655-62.

80. Coia LR, Engstrom PF, Paul AR, Stafford PM, Hanks GE. Long-term results of infusional 5-FU, mitomycin-C and radiation as primary management of esophageal carcinoma. Int J Radiat Oncol Biol Phys 1991; 20: 29-36.

81. Leichman L, Herskovic A, Leichman CG, et al. Nonoperative therapy for squamous-cell cancer of the esophagus. $J$ Clin Oncol 1987; 5: 365-70.

82. Kavanagh B, Anscer M, Leopold K, et al. Patterns of failure following combined modaliaty therapy for esophageal cancer, 1984-1990. Int J Radiat Oncol Biol Phys 1992; 24: $633-42$.

83. Herskovic A, Martz K, Al-Sarraf M, et al. Combined chemotherapy and radiotherapy compared with radiotherapy alone in patients with cancer of the esophagus. $N$ Engl J Med 1992; 326: 1593-8.

84. Forastiere A, Orringer MB, Perez-Tamayo C, et al. Concurrent chemotherapy and radiation therapy followed by transhiatal esophagectomy for loco-regional cancer of the esophagus. $J$ Clin Oncol 1990; 8: 119-27.

85. Pera M, Cameron AJ, Trastek VF, Carpenter HA, Zinsmeister AR. Increasing incidence of adenocarcinoma of the esophagus and esophagogastric junction. Gastroenterology 1993; 104: 510-3.

86. Van Dam J. Endosonographic evaluation of the patient with esophageal carcinoma. Chest Surg Clin North Am 1994; 4: 269-84.

87. Dagnini G, Caldironi MW, Marin G, Buzzaccarini O, Tremolada C, Ruol A. Laparoscopy in abdominal staging of esophageal carcinoma; report of 369 cases. Gastrointest Endosc 1986; 32: 400-2.

88. Sugarbaker DJ, Jaklitsch MT, Liptay MJ. Thoracoscopic staging and surgical therapy for esophageal cancer. Chest 1995; 107: 218S-223S.

\title{
Neoadjuvant treatment in oesophageal cancer: the needs for future trials
}

\author{
Tjebbe C. Kok* and Hugo W. Tilanus $\dagger$ \\ for the Rotterdam Esophageal Tumor Study Group, Departments of *Medical Oncology and †General \\ Surgery, University Hospital Rotterdam, Dijkzigt, Rotterdam, the Netherlands
}

\begin{abstract}
In view of the poor survival after surgery alone for oesophageal cancer, combination with chemotherapy seems rational. A concept of upfront chemotherapy is discussed and seems especially useful for these tumours. The published randomized trials, studying the effect of neoadjuvant chemotherapy do, however, not (yet) show an improved overall survival, apart from one study with a significant median survival benefit at an interim evaluation. The responding patients have in all trials a far better survival than the non-responders. The numbers of patients are small and results of other ongoing and future trials should be awaited. New trials testing high-dose chemotherapy with bone marrow support should be initiated.
\end{abstract}

Key words: oesophageal cancer; neoadjuvant treatment; trials.

The outlook for patients with oesophageal cancer is poor. Although peri-operative mortality has decreased substantially in the past decades, the 5-year survival rate is still about $10 \%$ or less in those patients with loco-regional disease who have been operated upon with curative intent. ${ }^{1,2}$ Micrometastatic dissemination resulting in a high proportion of regional and distant failures are common events, especially in Western patients, who may present late, and frequently have $\mathrm{T}_{3-4}, \mathrm{~N}+$ tumours. $^{3-6}$ The situation in Asia, China and Japan is different, as this tumour type is among the most frequently observed malignancies, and where screening programmes have certainly resulted in a high proportion of stage I patients, with good results after loco-regional treatment alone. This aside, it appears justified to consider a patient with loco-regional cancer of the oesophagus as having

Correspondence to: Tjebbe C. Kok, MD, Dept of Medical Oncology D-329, University Hospital Rotterdam, / Dijkzigt, Dr Molewaterplein 40, NL-3015 GD Rotterdam, the Netherlands. advanced disease at the time of diagnosis. The use of systemic treatment in combination with local modalities (surgery and/ or radiotherapy) seems rational.

Because of the relative rarity of this disease and the severe morbidity in many patients at the time of diagnosis, tumours of the oesophagus have not been systematically tested against a variety of cytostatic drugs. However, both squamous cell carcinoma and adenocarcinoma are chemotherapy-sensitive, with response rates of approximately $40-50 \%$ (somewhat less for adenocarcinomas) for various cisplatin-based combination regimens. ${ }^{\text {? }}$

What is the impact of timing of systemic therapy on the outcome? Should conventional post-operative adjuvant treatment be applied, as in node-positive breast cancer, or is there a rationale for pre-operative or neoadjuvant systemic treatment? Post-operative systemic chemotherapy after primary local treatment for oesophageal cancer has not been successful. After an oesophagectomy, whether by thoracotomy or by a transhiatal approach, many patients 
cannot be treated with systemic chemotherapy for a considerable time. It is impossible therefore to comply with the basic rule of adjuvant chemotherapy, that is to start systemic treatment as quick as possible. ${ }^{8}$ No randomized trials have been reported.

The concept of neoadjuvant chemotherapy has been developed to induce early tumour regression, with improved local control when followed by subsequent surgery and/or radiotherapy, and an ability to identify responding and nonresponding patients. ${ }^{9.10}$ In addition, several animal studies have shown an increase in the labelling index of metastases after resection of the primary tumour, and a better survival when chemotherapy was given before resection. ${ }^{11-14}$ Lastly, chemotherapy is likely to have a greater impact when given early in the course of the disease, when subclinical metastatic burden is low and the patient is best able to tolerate toxic side-effects.

Potential drawbacks of neoadjuvant chemotherapy include: the (theoretical) possibilities of delay in achieving local control; a risk of tumour spread from the primary site in case of a chemoresistant tumour; and the creation of an 'unnatural' tumour area with necrosis and fibrosis at the time of surgery in cases of chemosensitive cancers.

Several phase II trials have been published on preoperative chemotherapy in oesophageal cancer, especially in locally advanced disease. ${ }^{15}$

Major responses with cisplatin-based combination chemotherapy have been documented in 15 to $70 \%$ with complete pathological responses in 4 to $10 \%$ of patients. Operative mortality seems to be comparable to surgery alone. The combination of cisplatin on day 1 and 5fluorouracil on days $1-4$ has been studied extensively, and has become a standard, against which new combinations are being compared. ${ }^{16-19}$ Although pre-operative systemic treatment seems to be safe, and operability, resectability and post-operative mortality are comparable with surgery alone, no clear survival benefit has been demonstrated in the above-mentioned phase II trials, which, by their nature, are not appropriate for testing survival differences.

Until now, three prospective randomized trials have been published, comparing neoadjuvant chemotherapy followed by surgery vs surgery alone. Roth et al. treated 17 patients with epidermoid carcinoma after randomization with 2 cycles of cisplatin, vindesine and bleomycine before surgery, followed by a 6-month period of post-operative chemotherapy with cisplatin and vindesine. ${ }^{20}$ Although patients responding to chemotherapy had a significantly prolonged survival (median: $>20$ months), overall survival was no different for surgery alone or neoadjuvant chemotherapy with surgery. Resectability and postoperative complication rate were similar. Schlag et al. reported in 1992 the results of a randomized phase III study, in which the duration of pre-operative treatment was dependent on a response evaluation after only 1 cycle with cisplatin and 5-fluorouracil; patients with no change or progression were operated upon at once, while responding patients were treated with another 2 cycles. ${ }^{21}$ The response rate was $47 \%$. Chemotherapy was associated with more post-operative complications, like sepsis and respiratory problems, and overall survival was not influenced by neoadjuvant treatment (median 10 months), but, as in the study by Roth, responding patients had a prolonged survival (median: 13 months) when compared with non-responders (median: 5 months).

A 4-arm study was reported in 1992 by Nygaard et al., who randomized patients between surgery alone $(n=41)$, preoperative chemotherapy with cisplatin and bleomycin $(n=$ $50)$, pre-operative radiotherapy $(n=48)$, or pre-operative chemoradiotherapy $(n=47) .{ }^{22}$ No data concerning response evaluation after chemotherapy or chemoradiotherapy are available. Patients with pre-operative treatment had no survival benefit compared with surgery alone. Two prospective randomized trials were reported very recently in abstract form. Fok et al..$^{23}$ from Hong Kong presented results of a prospective randomized study on preoperative chemotherapy ( 2 cycles of cisplatin and 5fluorouracil) vs surgery alone. One hundred and sixty patients were randomized. There was a high resectability rate in both groups ( $88 \%$ vs $93 \%$ ), and a high response rate after chemotherapy, with $19 \%$ complete responses and $32 \%$ partial responses. Median survival was the same for both groups: 12 months. The 5-year survival rate for responding patients was $52 \%$, for non-responders $10 \%$, and for the control group $11 \%$. Kok et al. ${ }^{24}$ presented results of an interim analysis of a similar study in which the duration of pre-operative chemotherapy was dependent on the response evaluation after 2 cycles of chemotherapy with cisplatin and etoposide; in case of a clear response, another 2 cycles were given pre-operatively, and in case of no response, the patient was operated on at once. In this ongoing trial, approximately 100 patients were randomized. With a median follow-up of 17.5 months there was a statistically significant median survival benefit after chemotherapy, not only for responding patients but also for the chemotherapy group as a whole. Final results with a longer follow-up are needed to draw definitive conclusions.

Two large scale phase III trials are now underway: the US Intergroup trial ( $\mathrm{Nr} \mathrm{0113)} \mathrm{randomizing} \mathrm{more} \mathrm{than} 400$ patients with squamous cell carcinoma and adenocarcinoma to receive 3 neoadjuvant and 2 post-operative chemotherapy cycles with cisplatin and 5-fluorouracil vs surgery alone. This trial has recently stopped patient entry, and results are awaited. An ongoing European trial (the MRC trial from the UK) is investigating the effect of 2 cycles of chemotherapy with cisplatin and 5-fluorouracil followed by surgery vs surgery alone in patients with squamous- or adenocarcinoma. No definitive results from this trial will be available in the short-term.

Several phase II trials have discussed the value of neoadjuvant chemotherapy with concurrent radiotherapy, followed by resection. The rationale behind this may be the chance to eradicate a greater proportion of cells, including resistant subpopulations, from the start of treatment. ${ }^{25}$ Also a smaller tumour mass may be more sensitive to radiation because of better central oxygenation.

A non-randomized phase II study by the SWOG and RTOG in the US, treating more than 150 patients preoperatively with cisplatin and 5-fluorouracil plus $30 \mathrm{~Gy}$ of concurrent radiotherapy, resulted in a median survival of 12 months, which is no different from those found with surgery alone. ${ }^{26} \mathrm{~A}$ randomized French study published in 1994, using 2 short cycles of cisplatin and 5-fluorouracil, interspersed 
with $20 \mathrm{~Gy}$ of radiation followed by resection, showed no survival benefit in the experimental group of patients. ${ }^{27}$

Better results have been achieved with systemic chemotherapy and concurrent radiotherapy than with radiotherapy alone. Important data from such a randomized trial have been published by Herskovic et al. in 1992. ${ }^{28}$ The trial was stopped after the accumulated results in 121 patients demonstrated a significant advantage for survival in patients who received chemotherapy and concurrent radiotherapy. No long-term survival data have been published yet.

What can we learn from the data available so far? Surgery alone seems to remain the standard of care for surgically treatable patients. The completion of the above-mentioned phase III randomized trials need to be available before a definitive place for neoadjuvant chemotherapy can be established. In several trials a survival benefit has been shown for those patients manifesting a major objective response to neoadjuvant chemotherapy. Although a response to chemotherapy may not be a totally independent prognostic factor, an intensification of the known chemotherapy schedules with bone marrow support by colony stimulating factors, and the implementation of new active compounds, with the aim of increasing the response rate (especially complete responses), should be issues for forthcoming research. ${ }^{29.30}$ In the meantime the discovery of new tools to differentiate between responding and nonresponding patients as early as possible in the period of pre-operative treatment, perhaps even before the start of treatment, should be pursued. If, eventually, neoadjuvant treatment should result in a better survival after surgery, then a randomized study, evaluating the best local treatment: surgery vs radiotherapy, should be initiated, including quality of life measurements.

\section{References}

1. Earlam R, Cunha-Melo J. Oesophageal squamous cell carinoma: I. A critical review of radiotherapy. Br J Surg 1980; 67: $381-90$.

2. Müller JM, Erasmi H, Stelzner M, Zieren U, Pichlmaier H. Surgical therapy of oesophageal carcinoma. Br J Surg 1990; 77: 845-57.

3. Bosch A, Frias Z, Caldwell WL, Jaeschke WH. Autopsy findings in carcinoma of the esophagus. Acta Radiol Oncol 1979; 18: 103-335.

4. Mandard AM, Chasle J, Marnay J, et al. Autopsy findings in 111 cases of esophageal cancer. Cancer 1981; 48: 329-35.

5. Chan KW, Chan EY, Chan CW. Carcinoma of the esophagus. An autopsy study of 231 cases. Pathology 1986; 18: 400-5.

6. Law SYK, Fok M. Wong J. Patterns of recurrence after oesophagectomy for cancer. Clinical Implications. Abstracts volume, 6th World Congress of the ISDE, Milan, Italy, August 23-26, 1995: 26.

7. Ajani JA. Contributions of chemotherapy in the treatment of carcinoma of the esophagus: results and commentary. Semin Oncol 1994; 4: 474-82.

8. Sautner T, Hofbauer F, Depisch D, Schiessel R, Jakesz R. Adjuvant intraperitoneal cisplatin chemotherapy does not improve long-term survival after surgery for advanced gastric cancer. J Clin Oncol 1994; 12: 970-4.

9. Muggia FM, Gill I. Primary chemotherapy. In: DeVita VT Jr, Hellman S, Rosenberg SA (eds) Cancer: principles \& practice of oncology updates. Philadelphia, PA: Lippincott 1990: 1-12.

10. Harris DT, Mastrangelo MJ. Theory and application of early systemic therapy. Semin Oncol 1991; 18: 493-503.
11. Schatten WE. An experimental study of postoperative tumor metastases I. Growth of pulmonary metastases following total removal of primary leg tumor. Cancer 1958; 11: 455-9.

12. Simpson-Herren L, Sandford AH, Holmquist JP. Effects of surgery on the cell kinetics of residual tumor. Cancer Treat Rep 1976; 60: 1749-60.

13. Fisher B, Gunduz N, Saffer EA. Influence of the interval between primary tumor removal and chemotherapy on kinetics and growth of metastases. Cancer Res 1983; 43: 1488-92.

14. Pendergast WJ Jr, Drake WP, Mardiney Mr Jr. A proper sequence for the treatment of B16 melarioma: chemotherapy, surgery and immunotherapy. $J$ Natl Cancer Inst 1976: 57: $539-44$.

15. Ilson DH, Kelsen DP. Combined modality therapy in the treatment of esophageal cancer. Semin Oncol 1994; 4: 493-507.

16. Vignoud J, Visset J, Paineau J, Le Neel JC, Cuilliere P, Cussac A. Preoperative chemotherapy in squamous cell carcinoma of the esophagus: clinical and pathological analysis, 48 cases. Ann Oncol 1990; 1 (Suppl.): 45.

17. Ajani JA, Ryan B, Rich TA, et al. Prolonged chemotherapy for localised squamous carcinoma of the esophagus. Eur $J$ Cancer 1992; 28A: 880-4.

18. Hilgrenberg AD, Carey RW, Wilkins EW Jr, Choi NC, Mathisen DJ, Grillo HC. Preoperative chemotherapy, surgical resection, and selective postoperative therapy for squamous cell carcinoma of the esophagus. Ann Thorac Surg 1988; 45: $357-63$.

19. Kies MS, Rosen ST, Tsang TK, Shetty R, Schneider PA, Wallemark CB, Shields TW. Cisplatin and 5-fuorouracil in the primary management of squamous esophageal cancer. Cancer 1987; 60: 2156-60.

20. Roth JA, Pass HI, Flanagan MM. Graeber GM, Rosenberg JC, Steinberg S. Randomized clinical trial of preoperative and post-operative adjuvant chemotherapy with cisplatin. vindesine, and bleomycin for carcinoma of the oesophagus. $J$ Thorac Cardiovasc Surg 1988; 96: 242-8.

21. Schlag P. Randomisierte Studie zur präoperativen Chemotherapie beim Plattenepithelcarcinom des Oesophagus. Chirurg 1992; 63: 709-14.

22. Nygaard K, Hagen S, Hansen HS, et al. Preoperative radiotherapy prolongs survival in operable esophageal carcinoma: a randomized, multicenter study of preoperative radiotherapy and chemotherapy. The second Scandinavian trial in esophageal cancer. World J Surg 1992; 16: 1104-9.

23. Fok M, Law $S$, Wong J. Prospective randomised study on preoperative chemotherapy for resectable intrathoracic squamous cancer of the oesophagus. Abstracts volume, 6th World Congress of the ISDE. Milan, Italy, August 23-26, 1995: 139.

24. Kok TC. Tilanus HW, Lanschot van J, Siersema PD, Overhagen van $H$, Bosman $F$. Neoadjuvant chemotherapy in operable esophageal squamous cell cancer: a 3rd interim report. Abstracts volume, 6th World Congress of the ISDE. Milan, Italy, August 23-26, 1995: 139.

25. Vokes EE. Interactions of chemotherapy and radiation. Semin Oncol 1993; 20: 70-9.

26. Poplin E, Fleming T, Leichman L, et al. Combined therapies for squamous-cell carcinoma of the esophagus, a Southwest Oncology Group Study (SWOG-8037). J Clin Oncol 1987; 5: 622-8.

27. Le Prise E, Etienne PL, Meunier B, et al. A randomized study of chemotherapy, radiation therapy, and surgery versus surgery for localized squamous cell carcinoma of the esophagus. Cancer 1994; 73: 1779-84.

28. Herskovic A, Martz K. Al-Sarraf M, et al. Combined chemotherapy and radiotherapy compared with radiotherapy alone in patients with cancer of the esophagus. $N$ Engl J Med 1992; 326: 1593 -8.

29. Ajani JA, Roth JA, Ryan MB, Putnam JB, Pazdur R, Levin B. Gutterman JU, McMurtrey $M$. Intensive preoperative chemotherapy with colony-stimulating factor for resectable adenocarcinoma of the esophagus or gastroesophageal junction. J Clin Oncol 1993; 1: 22-8.

30. Ajani JA, Ilson DH, Daugherty K, Pazdur R, Lynch PM, Kelsen DP. Activity of Taxol in patients with squamous cell carcinoma and adenocarcinoma of the esophagus. $J$ Natl Cancer Inst 1994; 14: 1086-91. 